\title{
Neural respiratory drive during apnoeic events in obstructive sleep apnoea
}

\author{
Y.M. Luo*, H.D. Wu*, J. Tang*, C. Jolley\#, J. Steier", J. Moxham\#, \\ N.S. Zhong* and M.I. Polkey
}

ABSTRACT: For a given neural drive, oesophageal pressure during apnoeic episodes may differ from that during airflow, since inspiratory airflow and increased lung volume both reduce pressure generation. It was, therefore, hypothesised that diaphragm electromyography (EMG) may provide additional data to oesophageal pressure when used for the assessment of neural drive in patients with obstructive sleep apnoea, whose breathing is associated with variable airflow and changes in lung volume.

Neural respiratory drive was assessed using diaphragm EMG recorded from multipair oesophageal electrodes in 12 patients with obstructive sleep apnoea. Oesophageal pressure was also recorded.

The mean \pm SD inspiratory oesophageal pressure swing was $11.0 \pm 3.7 \mathrm{cmH}_{2} \mathrm{O}$ during wakefulness, $38.2 \pm 15.7 \mathrm{cmH}_{2} \mathrm{O}$ at the end of the apnoea and reduced to $28.5 \pm 10.4 \mathrm{cmH}_{2} \mathrm{O}$ at the beginning of arousal. The mean peak inspiratory diaphragm EMG signal was $21.8 \pm 6.5 \mu \mathrm{V}$ during wakefulness, $38.6 \pm 14.0 \mu \mathrm{V}$ at the end of the apnoea and further increased to $59.6 \pm 32.0 \mu \mathrm{V}$ at the beginning of arousal.

It was concluded that the pattern of neural drive assessed by oesophageal pressure differs from that measured by diaphragm electromyography during apnoeic events and, therefore, that diaphragm electromyography may be a useful adjunct to measurement of oesophageal pressure for the assessment of neural drive in patients with obstructive sleep apnoea.

KEYWORDS: Apnoea, breathing disorders during sleep, diaphragm, electrophysiology, neural control of respiration

$\mathbf{T}$ he activity of the respiratory muscles during apnoeic events in patients with obstructive sleep apnoea (OSA) is of clinical and scientific interest. In particular, understanding changes in neural drive may provide further insights regarding the nature of OSA. Clinically, it has been hypothesised that, during episodes of subtotal obstruction, increased inspiratory muscle activity occurs and that the arousals associated with these episodes can cause hypersomnolence, the upper airway resistance syndrome. From a scientific perspective, it is probable that the vigour of the response of the respiratory muscle pump to occlusion of the upper airway reflects the pattern of arousal, and so assessing this may give an insight into the nature of the arousals. In addition, loop gain has been postulated as a contributor to OSA in some patients with OSA [1], but accurately investigating this hypothesis would be facilitated by accurate measurement of neural drive.

For these reasons, it is sometimes considered worthwhile to measure oesophageal pressure (Poes) as a reflection of neural drive [2, 3]. However, Poes may vary during obstructive episodes, since inspiratory airflow and high lung volume both reduce pressure generation for a given level of neural drive. Therefore, Poes may not accurately reflect neural drive in patients with OSA, whose breathing, by definition, is associated with variable airflow and, conceivably, changes in lung volume. Despite these potential problems STOOHS et al. [4] reported in 2005 that diaphragm electromyography (EMG) activity recorded using surface electrodes enjoyed a close relationship with $P$ oes in patients with moderate OSA.

Since the early 2000s, it has been established that neural respiratory drive can be reliably measured using oesophageal diaphragm EMG in normal subjects and patients with respiratory disease if a multipair oesophageal electrode is employed [5, 6]. Moreover, signals from this type of oesophageal electrode are usually of better quality and easier to analyse than those obtained from surface electrodes [7]. Since this technique is feasible during sleep, it was hypothesised that continuous
AFFILIATIONS

*Guangzhou Medical College, The State Key Laboratory of Respiratory Disease, Guangzhou, China.

\#King's College Hospital, and 'Royal Brompton Hospital, London, UK.

CORRESPONDENCE

Y.M. LuO

Guangzhou Institute of Respiratory Diseases

151 Yanjiang Road

Guangzhou 510120

China

Fax: 862034284122

E-mail: yuanminglu09431@

yahoo.co.uk

Received:

April 232007

Accepted after revision:

November 082007

SUPPORT STATEMENT

This study was supported by the Chinese Ministry of Science and Technology, Beijing, China.

STATEMENT OF INTEREST None declared.

European Respiratory Journal Print ISSN 0903-1936 Online ISSN 1399-3003 
oesophageal diaphragm EMG might offer new insights into inspiratory muscle activity during apnoeic episodes in OSA. Although this has been attempted previously [8], the present approach benefits from a close array of multiple sensors to overcome the problem of electrode positioning, which could be particularly important as patients are likely to change posture during sleep.

The purpose of the present study was to determine whether the multipair oesophageal electrode can reliably and continuously record the diaphragm EMG signal during overnight polysomnography in patients with OSA and, in particular, to compare diaphragm EMG with Poes for the assessment of neural drive during apnoeic events in patients with OSA in order to consider whether or not the relationship described by STOOHS et al. [4] is the case throughout apnoea.

\section{METHODS}

In total, 12 male subjects aged $24-63$ yrs (mean age $41 \pm 12$ yrs) with suspected OSA were recruited from patients referred to the Sleep Centre of Guangzhou Institute of Respiratory Diseases (Guangzhou, China); their demographic data are shown in table 1 . No patient had coexisting conditions that were likely to affect respiratory muscle function, such as chronic obstructive pulmonary disease or neuromuscular disease. The present study was approved by the Ethics Committee of Guangzhou Institute of Respiratory Diseases, and all subjects gave their informed consent.

\section{The oesophageal electrode and its positioning}

The diaphragm EMG signal was recorded using a new version of a previously described catheter [5]. Briefly, it consisted of 10 electrode coils (fig. 1), each $10 \mathrm{~mm}$ in length and $1.9 \mathrm{~mm}$ in diameter, with a gap between adjacent recording coils of $0.5 \mathrm{~mm}$. Five pairs of electrodes were formed, with pair 1 consisting of coils 1 and 5 , pair 2 of coils 2 and 6 , pair 3 of coils 3 and 7, pair 4 of coils 4 and 8, and pair 5 of coils 5 and 9. On the catheter, another coil (coil 0), located $2 \mathrm{~cm}$ from coil 1, was

\begin{tabular}{|c|c|c|c|c|c|c|}
\hline Patient & $\begin{array}{l}\text { Age } \\
\text { yrs }\end{array}$ & $\begin{array}{c}\text { Height } \\
\text { cm }\end{array}$ & $\begin{array}{c}\text { Weight } \\
\text { kg }\end{array}$ & $\begin{array}{c}\text { BMI } \\
\mathrm{kg} \cdot \mathrm{m}^{-2}\end{array}$ & $\begin{array}{c}\text { AHI } \\
\text { events } \cdot h^{-1}\end{array}$ & $\begin{array}{c}\text { Sleep time } \\
\text { min }\end{array}$ \\
\hline 1 & 40 & 172 & 70 & 23.7 & 38 & 321 \\
\hline 2 & 42 & 176 & 74 & 23.9 & 60 & 391 \\
\hline 3 & 59 & 168 & 70 & 24.8 & 67 & 450 \\
\hline 4 & 48 & 160 & 75 & 29.3 & 54 & 486 \\
\hline 5 & 43 & 172 & 96 & 32.4 & 71 & 465 \\
\hline 6 & 63 & 165 & 75 & 27.5 & 63 & 404 \\
\hline 7 & 27 & 173 & 78 & 26.1 & 56 & 255 \\
\hline 8 & 35 & 175 & 85 & 27.8 & 70 & 241 \\
\hline 9 & 49 & 173 & 95 & 31.7 & 81 & 494 \\
\hline 10 & 24 & 163 & 75 & 28.2 & 100 & 360 \\
\hline 11 & 38 & 167 & 70 & 25.1 & 61 & 426 \\
\hline 12 & 29 & 170 & 90 & 31.1 & 83 & 389 \\
\hline Overall & $41 \pm 12$ & $170 \pm 5$ & $79 \pm 10$ & $27.6 \pm 3.0$ & $67 \pm 16$ & $390 \pm 84$ \\
\hline
\end{tabular}

Overall data are presented as mean \pm SD. All subjects were male. BMI: body mass index; AHI: apnoea/hypopnoea index connected to ground. The oesophageal electrode was passed through the nose and swallowed into the oesophagus. Coil 5 was positioned close to the crus of the diaphragm based on the spontaneous EMG recorded from the five pairs of electrodes [5]. The optimal position of the electrode catheter was characterised by large EMG signals recorded from electrode pairs 1 and 5, and a small EMG signal recorded from pair 3, during resting breathing, as previously described [5, 9]. After the oesophageal electrode was satisfactorily positioned with the subject in the supine position, the catheter was securely taped at the nose. The diaphragm EMG signals were amplified and band-pass filtered in the range 20-1,000 Hz.

Poes and gastric pressure $\left(P_{\text {ga }}\right)$ were recorded using balloon catheters that were positioned at the lower oesophagus and stomach [10]. The oesophageal balloon contained $0.5 \mathrm{~mL}$ of air and the gastric balloon $2 \mathrm{~mL}$, and pressures were measured by differential pressure transducers. Poes was measured in all 12 subjects, whereas only eight consented to have more than two catheters inside their body.

\section{Clinical polysomnography}

Conventional polysomnography was performed, including electroencephalography (C3/A2 and C4/A1), left and right electro-oculography, submental EMG and measurement of
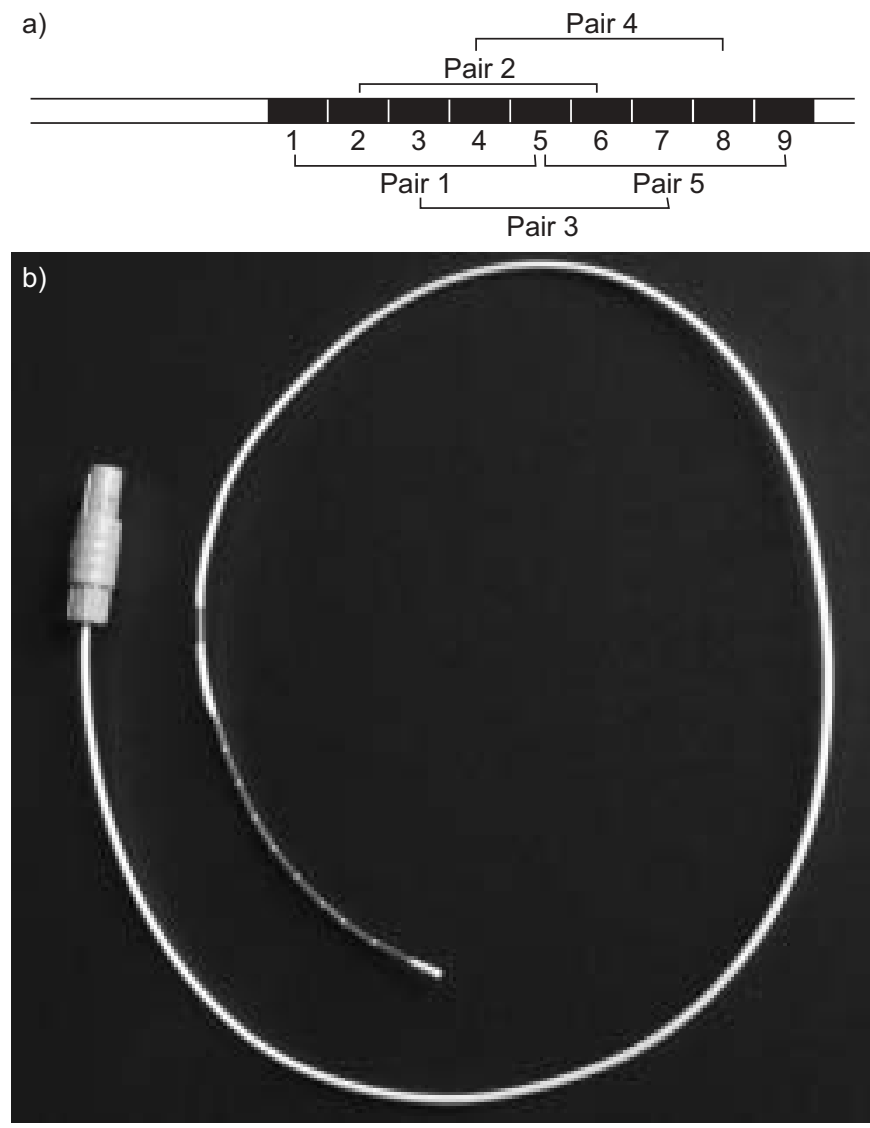

FIGURE 1. a) Configuration and b) photograph of a multipair oesophagea electrode catheter. The oesophageal electrode catheter contains 10 metal coils (numbered 0-9), each $1 \mathrm{~cm}$ in length. The distance between recording electrodes is $0.5 \mathrm{~mm}$ (brackets). Five pairs of electrodes were formed. 
airflow (thermistor), snoring, body position, thoracic and abdominal movements, and oxygen saturation. All signals were recorded by an Alice 4 system (Respironics Inc., Pittsburgh, PA, USA).

\section{Abdominal EMG}

The abdominal EMG was also recorded, using silver/silver chloride electrodes (3M Health Care, London, ON, Canada), in four subjects in order to aid understanding of the changes in end-expiratory Poes. The electrodes were positioned $2 \mathrm{~cm}$ to the right of the navel, with a $3-\mathrm{cm}$ interelectrode distance.

Signals were recorded and analysed using an Apple computer and Powerlab system (ADInstruments, Castle Hill, Australia). The sampling frequency was $2 \mathrm{kHz}$ for diaphragm EMG and $200 \mathrm{~Hz}$ for other signals. Transdiaphragmatic pressure (Pdi) was calculated by digital subtraction of $P$ oes from $P$ ga.

\section{Data analysis}

Data were analysed offline. The root mean square (RMS) of the EMG signal was calculated by computer using a time constant of 100 ms. The RMS reported was that of the electrode pair with the greatest EMG signal amplitude for each breathing cycle. In order to avoid influence of ECG on diaphragm EMG, RMS was measured from segments between QRS complexes. Apnoea was defined as the absence of airflow for $>10 \mathrm{~s}$, during which there were thoracic and abdominal movements. Five to eight apnoeic episodes were selected for analysis for each subject during stage II sleep in the supine position; very little stage III/IV sleep was observed due to the severity of the present patients. In addition, the apnoeas selected for analysis were those with three or more breaths with airflow following the apnoea. Each apnoea was divided into beginning (the first respiratory effort without airflow), middle (based on the number of respiratory efforts during the apnoea) and end (the last respiratory effort without airflow), and data from a single respiratory cycle were analysed at each time-point. For the purposes of the present study, rest is defined as five to eight breaths chosen during relaxed supine wakefulness, and arousal as the mean of the first breaths associated with airflow after arousal for each apnoea. Data are presented as mean \pm SD. Paired t-tests and one-way ANOVA were applied to examine for differences.

\section{RESULTS}

The oesophageal electrode with 10 electrode coils was tolerated by all the subjects, who achieved a total sleep time of $390 \pm 84 \mathrm{~min}$. Clinical sleep data are shown in table 1 .

Good quality signals could be recorded continuously from the five pairs of electrodes; an example is shown in figure 2. The electrode pair that recorded a large EMG signal at the beginning of a study was usually the same or adjacent to the pair recording the maximum EMG signal at the end of the study.

\section{EMG changes during OSA}

The RMS of the EMG signal at the end of an apnoea $(38.6 \pm 14.0 \mu \mathrm{V})$ was always larger than that at the beginning of the apnoea $(25.3 \pm 6.9 \mu \mathrm{V} ; \mathrm{p}<0.01)$. The greatest EMG activity was observed at the beginning of the arousal rather than at the end of the apnoea (figs 2 and 3) in all the subjects except one (patient 3). Data are shown in table 2. There was significant difference in the RMS of the EMG signal between the arousal and the end of the apnoea $(59.6 \pm 32.0$ versus $38.6 \pm 14.0 \mu \mathrm{V} ; \mathrm{p}<0.01)$.

The RMS of the diaphragm EMG signal in the supine position during resting wakefulness $(21.8 \pm 6.5 \mu \mathrm{V})$ did not differ significantly between the beginning $(25.3 \pm 6.9 \mu \mathrm{V})$ and the middle $(23.0 \pm 4.7 \mu \mathrm{V})$ of an apnoea. However, the RMS of the diaphragm EMG signal at the end of the apnoea was significantly greater than that at rest or at the beginning of the apnoea $(\mathrm{p}<0.01)$.

\section{Change in end-expiratory Poes and rectus muscle EMG signal during OSA}

The mean end-expiratory Poes at the beginning of an OSA episode was $9.4 \pm 5.0 \mathrm{cmH}_{2} \mathrm{O}$ and remained almost unchanged until the middle of the apnoea $\left(9.7 \pm 4.8 \mathrm{cmH}_{2} \mathrm{O}\right)$, but increased significantly to $12.2 \pm 5.3 \mathrm{cmH}_{2} \mathrm{O}$ at the end of the apnoea $(p<0.05$; fig. 4). The rectus muscle EMG signal during expiration was silent at the beginning of an OSA episode and became active at the end of the apnoea (fig. 4).

\section{Comparison of diaphragm EMG signal and Poes or Pdi during OSA}

The $P$ oes and $P$ di changes during apnoeic episodes are shown in tables 3 and 4; Poes was lowest at rest (table 3 ) and gradually increased during the course of the apnoea. Poes at the end of an apnoea $\left(38.2 \pm 15.7 \mathrm{cmH}_{2} \mathrm{O}\right)$ was almost twice as high as that the beginning of the apnoea $\left(20.6 \pm 9.0 \mathrm{cmH}_{2} \mathrm{O} ; \mathrm{p}<0.01\right)$. Similarly, Pdi also gradually increased over the course of the apnoea. $P$ di at the end of an apnoea $\left(29.1 \pm 4.3 \mathrm{cmH}_{2} \mathrm{O}\right)$ was much higher than at the beginning $\left(18.3 \pm 4.2 \mathrm{cmH}_{2} \mathrm{O} ; \mathrm{p}<0.01\right)$. Importantly, in contrast to the changes in diaphragm EMG, the observed swings in Poes and Pdi were usually lower during arousal than at the end of the apnoea. Although Poes and Pdi increased gradually over the apnoea episode in all subjects, the RMS of the EMG signal was similar during wakefulness and the beginning and middle of the OSA event but increased substantially with arousal (fig. 3). The relationship between Poes and diaphragm EMG signal was good during apnoea $(\mathrm{r}=0.93)$, but became weak when airflow resumed $(\mathrm{r}=0.59)$. Similarly, the relationship between Pdi and diaphragm EMG signal was also good during apnoea $(r=0.94)$, and became weak when airflow resumed $(\mathrm{r}=0.75)$.

\section{DISCUSSION}

The main finding of the present study was that assessment of neural drive using oesophageal diaphragm EMG is feasible in patients with OSA. Neural respiratory drive was usually decreased rather than increased during apnoeic events. The present data show that, when judged by diaphragm EMG rather than pleural pressure, the highest neural drive is observed during the arousal phase and that, during this phase, the close relationship between diaphragm EMG signal and pleural pressure is lost.

\section{Critique of the method}

It is acknowledged that the present data set comes from a relatively small number of subjects studied in a specialist laboratory, and that trained physiologists analysed the data by hand. Nevertheless, the present authors believe that, if desired, the technique could be automated in the future, and that a 


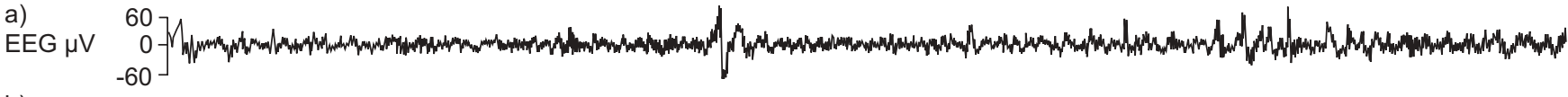

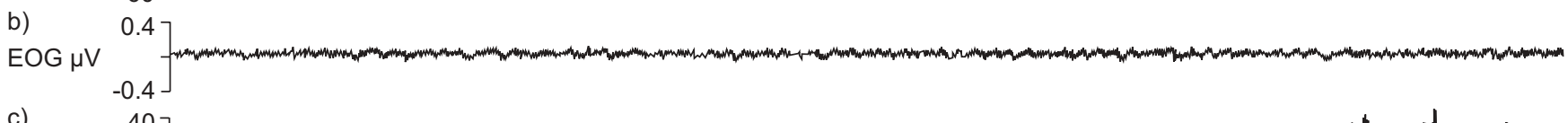

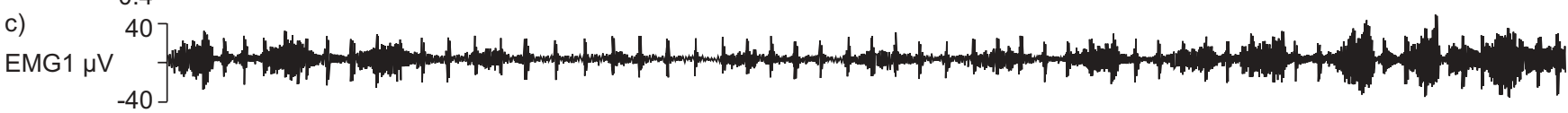

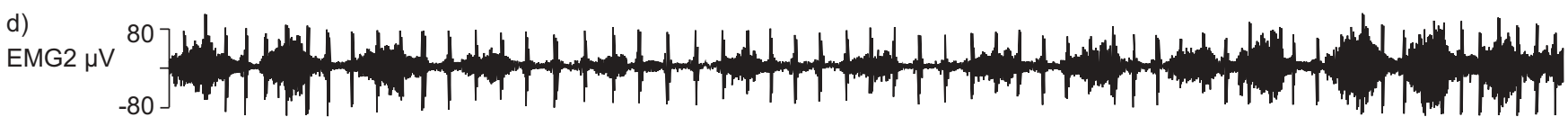

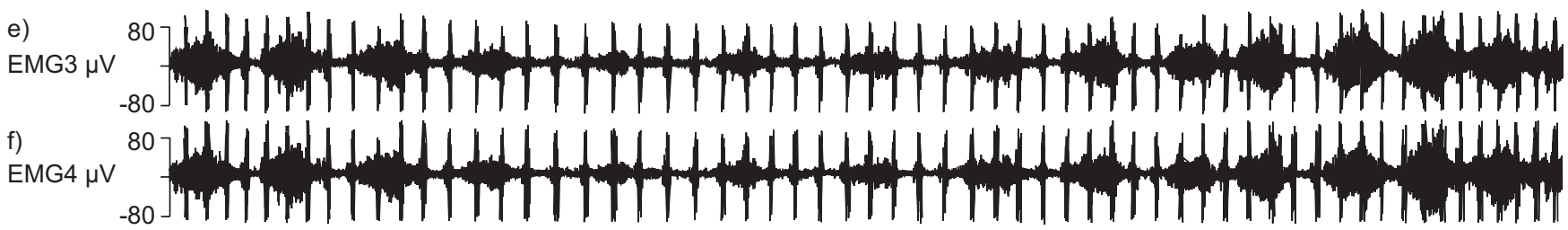

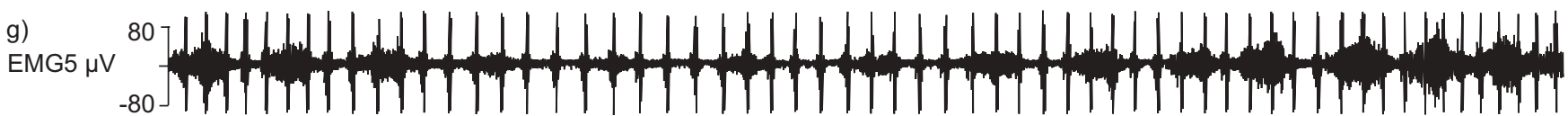
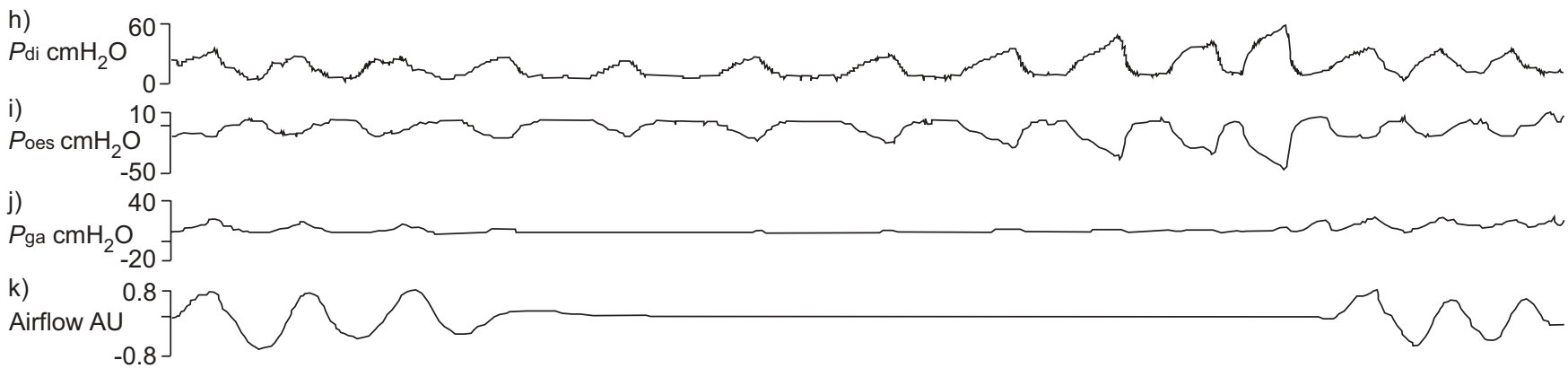
l) $\quad 0.008$ Snoring AU $-0.008$

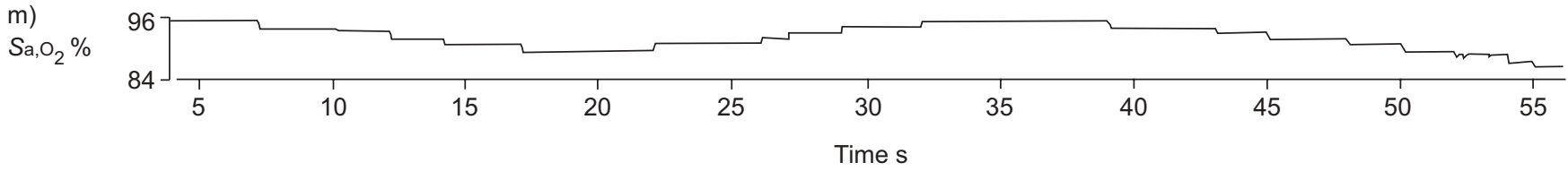

FIGURE 2. a) Electroencephalogram (EEG; C4/A1); b) electro-oculogram (EOG) from left outer canthus electrode; c-g) diaphragm electromyograms (EMGs), each recorded from one of the five pairs of electrodes; h) transdiaphragmatic pressure (Pdi); i) oesophageal pressure (Poes); j) gastric pressure (Pga); k) airflow from nasal pressure; l) snoring; and $\mathrm{m}$ ) arterial oxygen saturation $\left(\mathrm{Sa}, \mathrm{O}_{2}\right)$. Both $P_{\text {oes }}$ and $P$ di increased gradually from the beginning until the end of the apnoea and suddenly decreased at the point of arousal. Diaphragm EMG activity from the five pairs of electrodes increased from the beginning to the end of the apnoea and further increased at the first breath of arousal. Data are from stage II sleep in one subject. AU: arbitrary unit.

technique for identifying and gating the ECG, as used by STOOHS et al. [4], would probably be necessary. The authors also accept that, from a clinical perspective, a diagnosis that can be used for treatment decisions can be made using a respiratory sleep study alone for many patients with OSA [11]; however, as discussed hereafter, the present authors believe the current observations also to be of interest in some clinical situations. It might be suggested that the oesophageal instrumentation itself would disturb sleep, but this was not the case in the present patients, as evidenced by their total sleep time. Finally, it should be noted that the present patients exhibited a lower body mass index than might be observed for their severity of sleep-disordered breathing, but were exclusively of Chinese heritage and such individuals are recognised to show OSA and upper airway resistance syndrome with a lower body mass index than Caucasian subjects.

\section{Significance of the findings}

Although diaphragm EMG is accepted as a sound technique for the assessment of neural drive during wakefulness, this parameter has not been widely used in sleep physiology because it is technically difficult to record good quality EMGs from chest wall surface electrodes [7, 12], since such electrodes also register activity of the ribcage and abdominal muscles. In 


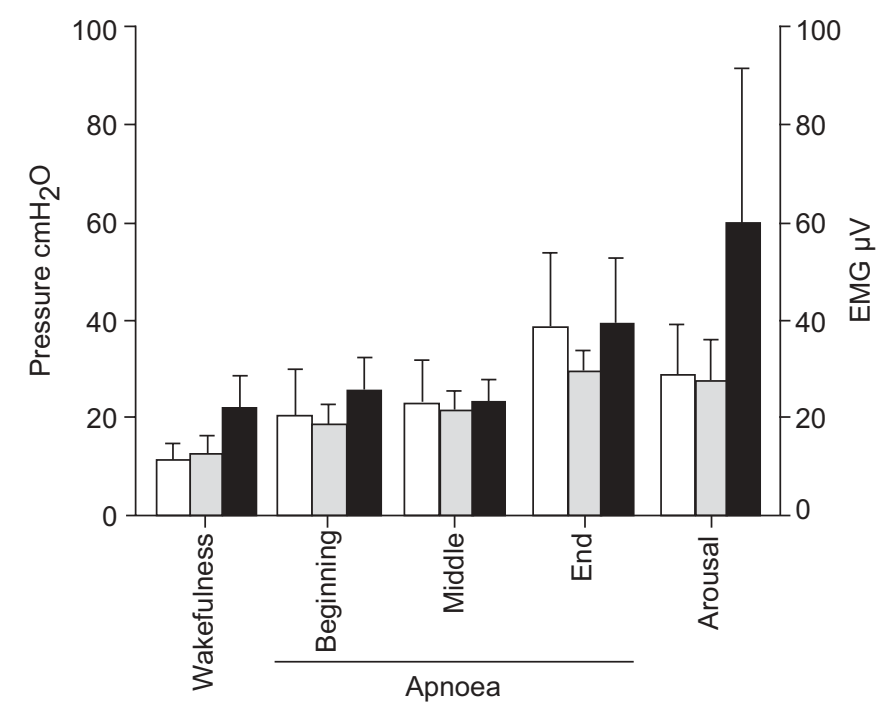

FIGURE 3. Oesophageal pressure (Poes; $\square$ ), transdiaphragmatic pressure (Pdi; $\left.{ }^{-1}\right)$ and diaphragm electromyography (EMG; $\left.\mathbf{\square}\right)$ signal recorded from the oesophageal electrode during obstructive sleep apnoea. Data are presented as mean \pm SD. Poes and $P$ di increased gradually over the course of an apnoea, reaching a maximum at the end of the apnoea, and decreased significantly at the beginning of arousal. However, the diaphragm EMG signal was similar at the beginning and middle of the apnoea, increased significantly at the end of the apnoea $(p<0.01)$ and increased further at the beginning of arousal $(p<0.01)$.

contrast, the diaphragm EMG signal recorded from oesophageal electrodes is relatively free of contamination from other muscles. Historically, such electrodes have been considered difficult to position with accuracy; indeed some investigators have considered it necessary to anchor the electrode with a gastric balloon in order to obtain adequate signals [13]. Since this anchoring gives an uncomfortable sensation and, by movement of the balloon with respiration, creates an additional artefact [14], it limits the usefulness of the technique for studies while patients are asleep.

However, it has previously been shown that an oesophageal catheter with closely spaced multipair electrodes can record the diaphragm EMG signal reliably for significant periods of time in patients with chronic obstructive pulmonary disease [5], those with neuromuscular disease [15] and normal subjects $[7,9]$. The present data show that the diaphragm EMG signal can be reliably and continually recorded during overnight sleep studies.

Recently, STоOHs et al. [4] made a comparison of Poes and diaphragm EMG signal recorded with surface electrodes in patients with OSA and concluded that changes in Poes were similar to changes in diaphragm EMG signal during apnoeic events. In the present study, this relationship was confirmed but, importantly, it was shown that the relationship is not robust after the resumption of airflow. The difference between the present results and those of SтоOHS et al. [4] could be partially explained by the difference in methodologies, as well as by the known effect of the pressure-flow relationships. Sтоонs et al. [4] used chest wall surface electrodes, which are subject to contamination from other muscles, as mentioned previously. Moreover, some useful diaphragm EMG signal, in

\begin{tabular}{|c|c|c|c|c|c|}
\hline \multirow{3}{*}{$\begin{array}{l}\text { TABLE } 2 \\
\text { Patient }\end{array}$} & \multicolumn{5}{|c|}{$\begin{array}{l}\text { Root mean square of diaphragm } \\
\text { electromyography signal\# }{ }^{\#} \text { during an obstructive } \\
\text { sleep apnoea event }\end{array}$} \\
\hline & \multirow[t]{2}{*}{ Rest } & \multicolumn{3}{|c|}{ Apnoea } & \multirow[t]{2}{*}{ Arousal } \\
\hline & & Beginning & Middle & End & \\
\hline 1 & 28.3 & 25.0 & 19.4 & 31.6 & 34.6 \\
\hline 2 & 24.4 & 24.9 & 19.4 & 49.7 & 77.5 \\
\hline 3 & 20.9 & 24.4 & 24.1 & 36.5 & 30.8 \\
\hline 4 & 17.3 & 20.2 & 23.2 & 26.7 & 40.7 \\
\hline 5 & 35.0 & 22.6 & 22.8 & 73.8 & 110.2 \\
\hline 6 & 15.7 & 19.9 & 19.1 & 26.8 & 28.4 \\
\hline 7 & 13.5 & 26.7 & 27.5 & 35.7 & 48.3 \\
\hline 8 & 19.8 & 21.3 & 23.2 & 29.4 & 45.5 \\
\hline 9 & 24.7 & 45.1 & 32.4 & 50.1 & 103.8 \\
\hline 10 & 21.8 & 24.6 & 16.7 & 31.8 & 60.5 \\
\hline 11 & 13.0 & 20.0 & 18.7 & 26.7 & 27.2 \\
\hline 12 & 26.7 & 29.2 & 29.1 & 44.9 & 107.4 \\
\hline Overall & $21.8 \pm 6.5$ & $25.3 \pm 6.9$ & $23.0 \pm 4.7$ & $38.6 \pm 14.0$ & $59.6 \pm 32.0$ \\
\hline
\end{tabular}

particular the high-frequency component, may have been lost because the settings of the band-pass filters for the diaphragm EMG were rather narrowly set in their study [16] and the sampling frequency for the diaphragm EMG was lower than in the present study.

The changes in Poes during OSA events are of interest. At the end of an apnoea, increased end-expiratory Poes was observed (fig. 4); in the absence of expiratory muscle activity, this would indicate air trapping (implying an increase in functional residual capacity), presumably due to obstruction of the upper airway in this context. Although apnoea is defined as a cessation of airflow, a barely detectable airflow may be continuing, and increasing functional residual capacity may serve to mitigate the OSA [17, 18]. However, an alternative and, the present authors believe, more plausible explanation is that contraction of the abdominal muscles [19], as evidenced by the rectus muscle EMG, is the cause of increasing endexpiratory Poes. It has previously been observed, in patients with chronic obstructive pulmonary disease, that increasing neural drive to the inspiratory muscles is associated with increased drive to the expiratory muscles, and that selective unloading of the inspiratory muscles reduces expiratory muscle activity [20].

It is usually considered that, at least during nonrapid eye movement sleep, the respiratory muscles, including the diaphragm, work hard to overcome upper airway resistance based on the observation that Poes swings increase during OSA episodes and fall during arousal [21]. Indeed, some investigators have hypothesised that respiratory muscle fatigue would occur in patients with severe OSA $[22,23]$. In keeping with this hypothesis, GRIGGS et al [22] reported a prolonged relaxation rate of inspiratory muscle in patients with sleep apnoea. In contrast, MONTSERRAT et al. [21] and CiBELla et al. [24], using the technique of diaphragm EMG frequency analysis, were unable 


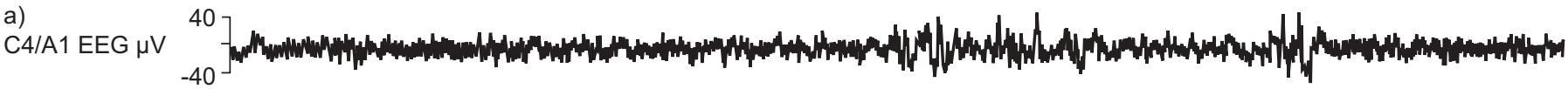

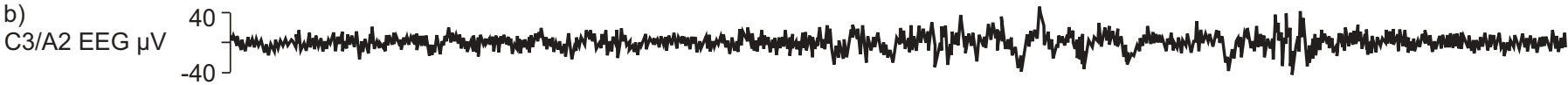

c)

EOG $\mu \mathrm{V}$

d)

EMG1 $\mu \mathrm{V}$

$\left.\begin{array}{c}0.2 \\ -0.2\end{array}\right]$

e)

EMG2 $\mu \mathrm{V}$

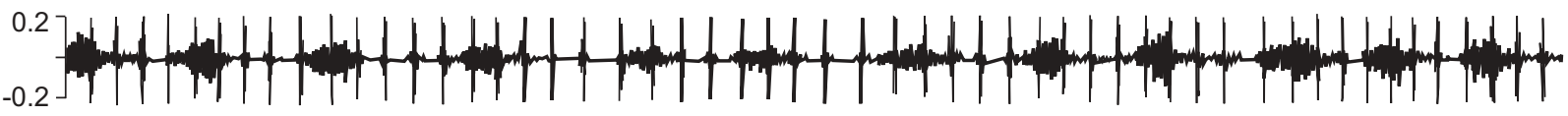
120

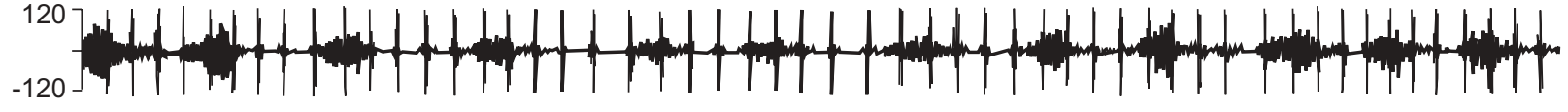

f)

EMG3 $\mu \mathrm{V}$

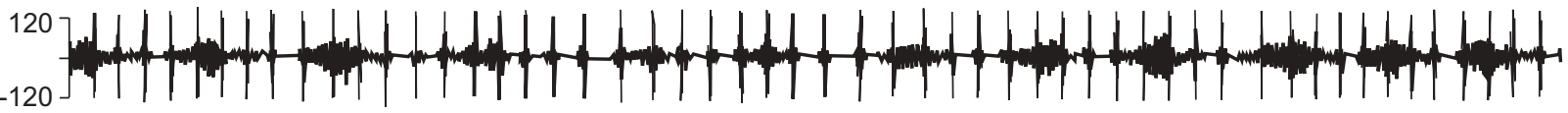

g)

EMG4 $\mu \mathrm{V}$

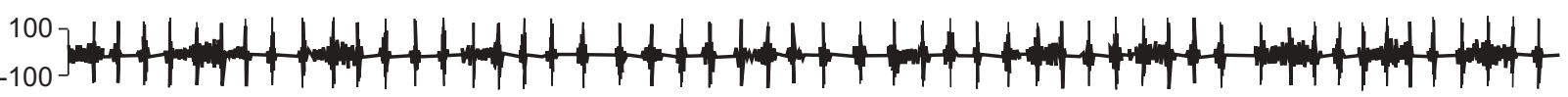

h)

EMG5 $\mu \mathrm{V}$

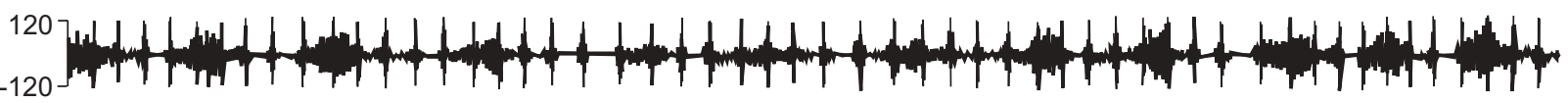

i)

EMGab $\mu \mathrm{V}$

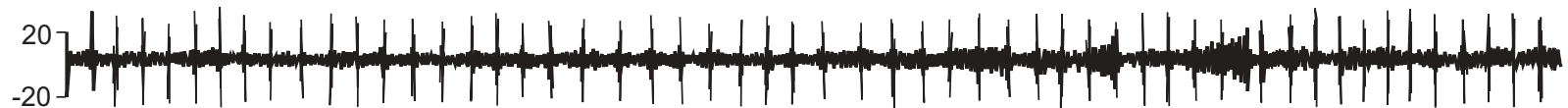

j)

Poes $\mathrm{cmH}_{2} \mathrm{O}$

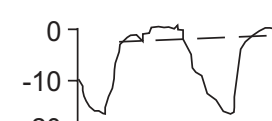

$\left.\begin{array}{c}-20 \\ -30 \\ -40\end{array}\right]$
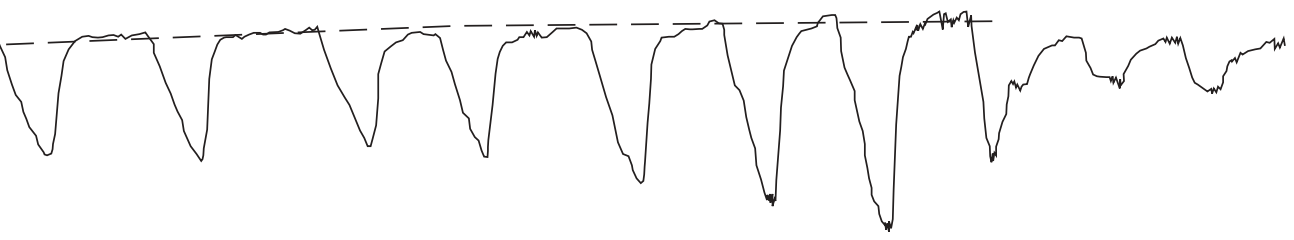

k)

$\mathrm{Pga}_{\mathrm{CmH}} \mathrm{O}$
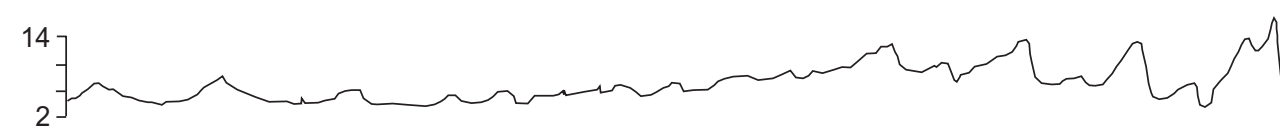

I) Airflow AU

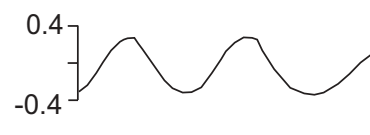

m)

Snoring AU

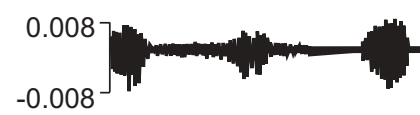

n)

$\mathrm{Sa}_{\mathrm{a}} \mathrm{O}_{2} \%$

100

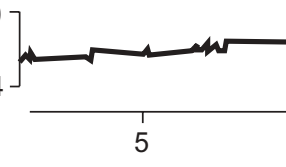

10

15

20

25

30

35

40

45

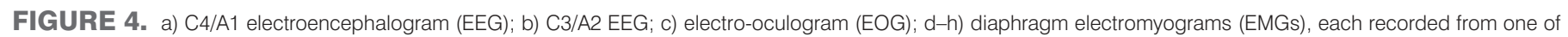

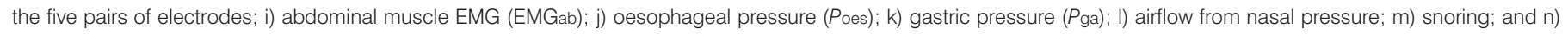

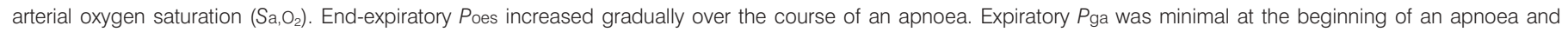

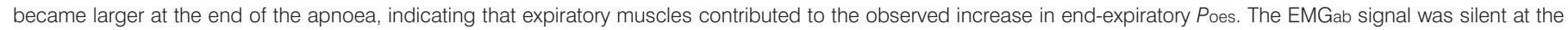

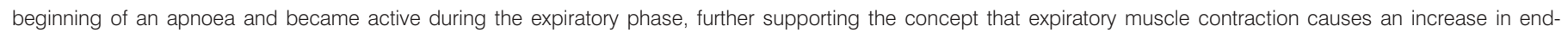
expiratory Poes. Data are from one subject. AU: arbitrary unit. 


\begin{tabular}{|c|c|c|c|c|c|}
\hline TABLE & $\begin{array}{l}\text { Oes } \\
\text { obs }\end{array}$ & $\begin{array}{l}\text { phageal } p \\
\text { uctive slee }\end{array}$ & $\begin{array}{l}\text { essure }\left(P_{0}\right. \\
\text { apnoea }\end{array}$ & $\begin{array}{l}\text { s) during } \\
\text { vent }\end{array}$ & \\
\hline \multirow[t]{3}{*}{ Patient } & \multicolumn{5}{|c|}{ Poes $\mathrm{cmH}_{2} \mathrm{O}$} \\
\hline & \multirow[t]{2}{*}{ Rest } & \multicolumn{3}{|c|}{ Apnoea } & \multirow[t]{2}{*}{ Arousal } \\
\hline & & Beginning & Middle & End & \\
\hline 1 & 7.4 & 18.6 & 23.8 & 35.0 & 27.5 \\
\hline 2 & 9.9 & 19.0 & 17.5 & 31.9 & 30.8 \\
\hline 3 & 9.7 & 14.8 & 17.2 & 26.3 & 18.1 \\
\hline 4 & 11.3 & 21.9 & 22.2 & 34.6 & 24.5 \\
\hline 5 & 16.0 & 15.4 & 18.8 & 68.8 & 39.8 \\
\hline 6 & 12.7 & 26.5 & 28.6 & 44.2 & 34.6 \\
\hline 7 & 12.5 & 20.6 & 22.7 & 30.4 & 20.8 \\
\hline 8 & 11.4 & 15.1 & 22.0 & 31.9 & 24.0 \\
\hline 9 & 16.9 & 45.5 & 46.3 & 70.8 & 51.3 \\
\hline 10 & 4.1 & 9.9 & 11.3 & 23.7 & 14.7 \\
\hline 11 & 6.6 & 23.2 & 25.1 & 35.7 & 20.7 \\
\hline 12 & 13.3 & 17.2 & 20.0 & 25.7 & 35.2 \\
\hline Overall & $11.0 \pm 3.7$ & $20.6 \pm 9.0$ & $22.9 \pm 8.6$ & $38.2 \pm 15.7$ & $28.5 \pm 10.4$ \\
\hline
\end{tabular}

Overall data are presented as mean $\pm \mathrm{SD}$

to collect enough evidence to support the hypothesis that diaphragm fatigue occurred in patients with severe OSA after repeated overnight apnoeic episodes. Finally, EL-KABIR et al. [25] used the technique of phrenic nerve stimulation to look for low-frequency fatigue of the diaphragm after one night's sleep in patients with severe OSA, but found no evidence of fatigue. Thus, it seems unlikely that clinically important peripheral fatigue occurs in patients with OSA. It has previously been shown that diaphragm fatigue during testing to task failure mainly occurs due to central fatigue $[9,26]$. In the present study, a brisk increase in neural drive to the diaphragm during arousal was shown in OSA, indicating no central failure of diaphragm activation. Since there is a decrease in the RMS of the diaphragm EMG signal during OSA events, it was therefore postulated that a decrease in neural drive may contribute to OSA episodes.

Poes is another option for the measurement of neural drive. However, this parameter is influenced by factors other than drive, notably airflow, increased lung volumes and decreased airway resistance, which reduce pressure generation. Thus, thresholds for respiratory muscle fatigue obtained from subjects whose breathing was accompanied by airflow would not be the same as those from OSA patients, whose breathing, by definition, occurs without airflow during apnoeic episodes. The present authors suggest that, since diaphragm EMG is free from these considerations, it may be an alternative method for the assessment of neural drive in patients with OSA, and previous studies have shown a good relationship between EMG signal and force generation [15]. It is of note that diaphragm EMG signal amplitude, independent of small and moderate changes in lung volume, can be accurately recorded from a multipair oesophageal electrode [5, 6, 9, 27, 28]. Neural drive can also be assessed by drive to the extradiaphragmatic

\begin{tabular}{|c|c|c|c|c|c|}
\hline TABLE & $\begin{array}{l}\text { Tran } \\
\text { obst }\end{array}$ & $\begin{array}{l}\text { liaphragm } \\
\text { ctive sleer }\end{array}$ & $\begin{array}{l}\text { ic pressu } \\
\text { apnoea e }\end{array}$ & $(P$ di $)$ dur & g an \\
\hline \multirow[t]{3}{*}{ Patient } & \multicolumn{5}{|c|}{$P_{\text {di }} \mathrm{cmH}_{2} \mathrm{O}$} \\
\hline & \multirow[t]{2}{*}{ Rest } & \multicolumn{3}{|c|}{ Apnoea } & \multirow[t]{2}{*}{ Arousal } \\
\hline & & Beginning & Middle & End & \\
\hline 1 & 11.4 & 18.1 & 22.7 & 34.4 & 28.4 \\
\hline 3 & 13.5 & 16.4 & 19.2 & 28.8 & 21.2 \\
\hline 4 & 14.6 & 22.4 & 22.4 & 33.6 & 28.9 \\
\hline 7 & 15.9 & 20.9 & 22.4 & 27.0 & 22.9 \\
\hline 8 & 15.2 & 16.7 & 23.8 & 26.4 & 36.0 \\
\hline 10 & 6.0 & 10.1 & 11.2 & 22.8 & 19.7 \\
\hline 11 & 8.6 & 23.5 & 24.3 & 33.6 & 16.4 \\
\hline 12 & 16.2 & 18.2 & 21.1 & 26.2 & 41.9 \\
\hline Overall & $12.7 \pm 3.7$ & $18.3 \pm 4.2$ & $20.9 \pm 4.2$ & $29.1 \pm 4.3$ & $26.9 \pm 8.7$ \\
\hline
\end{tabular}

muscles. Interestingly, BERRY et al. [29] measured the genioglossus EMG signal during apnoeic episodes and it is evident (upper panel of figure 1 of their data) that the same postarousal dissociation between genioglossus EMG signal and Poes can be observed as is described herein for the diaphragm.

One application of EMG technology could be the diagnosis of upper airway resistance syndrome. Currently, diagnosis of this condition requires the demonstration of increased Poes swings related to arousal $[30,31]$. The present authors suggest that oesophageal diaphragm EMG may be more sensitive than pressure measurement and, indeed, if variations in diaphragm EMG signal were sufficiently different in upper airway resistance syndrome patients from normal subjects, it could possibly be used on its own as a diagnostic test. This would be particularly appealing for the present authors' clinical research group since upper airway resistance syndrome is more common in patients of Far Eastern heritage [32]. A further potential application is the distinction of central from obstructive apnoea, and particularly hypopnoea, which could be difficult based on conventional polysomnography [33]. This distinction is particularly important in patients with heart failure, given that continuous positive airway pressure is beneficial in patients with OSA but not Cheyne-Stokes respiration [34]. Conventionally, central hypopnoea is defined as a reduction in flow proportional to the decrease in respiratory drive [33]. In this context, it becomes important to accurately assess neural respiratory drive in order to distinguish central from obstructive hypopnoea. Although Poes is commonly used to assess neural respiratory drive, it is affected, as the present data demonstrate, by changes in lung volume and airflow. Therefore, EMG may be particularly valuable for the evaluation of hypopnoea, where changes in lung volume and airflow occur, rather than apnoea.

In conclusion, neural drive during apnoeic episodes in patients with obstructive sleep apnoea can be reliably measured using oesophageal diaphragm electromyography. In contrast to data obtained using oesophageal or transdiaphragmatic pressure, 
the present data show that the highest neural drive occurs during arousal rather than during apnoea.

\section{REFERENCES}

1 Wellman A, Jordan AS, Malhotra A, et al. Ventilatory control and airway anatomy in obstructive sleep apnea. Am J Respir Crit Care Med 2004; 170: 1225-1232.

2 Stoohs R, Guilleminault C. Snoring during NREM sleep: respiratory timing, esophageal pressure and EEG arousal. Respir Physiol 1991; 85: 151-167.

3 Chervin RD, Aldrich MS. Effects of esophageal pressure monitoring on sleep architecture. Am J Respir Crit Care Med 1997; 156: 881-885.

4 Stoohs RA, Blum HC, Knaack L, Butsch-von-der-Heydt B, Guilleminault C. Comparison of pleural pressure and transcutaneous diaphragmatic electromyogram in obstructive sleep apnea syndrome. Sleep 2005; 28: 321-329.

5 Luo YM, Moxham J. Measurement of neural respiratory drive in patients with COPD. Respir Physiol Neurobiol 2005; 146: 165-174.

6 Sinderby C, Spahija J, Beck J, et al. Diaphragm activation during exercise in chronic obstructive pulmonary disease. Am J Respir Crit Care Med 2001; 163: 1637-1641.

7 Luo YM, Polkey MI, Johnson LC, et al. Diaphragm EMG measured by cervical magnetic and electrical phrenic nerve stimulation. J Appl Physiol 1998; 85: 2089-2099.

8 Onal E, Lopata M. Respiratory muscle interaction during NREM sleep in patients with occlusive apnoea. J Appl Physiol 1986; 61: 1891-1895.

9 Luo YM, Hart N, Mustfa N, Lyall RA, Polkey MI, Moxham J. Effect of diaphragm fatigue on neural respiratory drive. J Appl Physiol 2001; 90: 1691-1699.

10 Luo YM, Hart N, Mustfa N, et al. Reproducibility of twitch and sniff transdiaphragmatic pressures. Respir Physiol Neurobiol 2002; 132: 301-306.

11 West SD, Jones DR, Stradling JR. Comparison of three ways to determine and deliver pressure during nasal CPAP therapy for obstructive sleep apnoea. Thorax 2006; 61: 226-231.

12 Luo YM, Polkey MI, Lyall RA, Moxham J. Effect of brachial plexus co-activation on phrenic nerve conduction time. Thorax 1999; 54: 765-770.

13 Gandevia SC, McKenzie DK. Human diaphragmatic EMG: changes with lung volume and posture during supramaximal phrenic stimulation. J Appl Physiol 1986; 60: 1420-1428.

14 Luo YM, Lyall RA, Harris ML, et al. Effect of lung volume on the oesophageal diaphragm EMG assessed by magnetic phrenic nerve stimulation. Eur Respir J 2000; 15: 1033-1038.

15 Luo YM, Lyall RA, Harris ML, Rafferty GF, Polkey MI, Moxham J. Quantification of the oesophageal diaphragm electromyogram with magnetic phrenic nerve stimulation. Am J Respir Crit Care Med 1999; 160: 1629-1634.

16 Schweitzer TW, Fitzgerald JW, Bowden JA, LynneDavies P. Spectral analysis of human inspiratory diaphragmatic electromyograms. J Appl Physiol 1979; 46: 152-165.

17 Sériès F, Cormier Y, Lampron N, La Forge J. Increasing the functional residual capacity may reverse obstructive sleep apnea. Sleep 1988; 11: 349-353.
18 Hoffstein V, Zamel N, Phillipson EA. Lung volume dependence of pharyngeal cross-sectional area in patients with obstructive sleep apnoea. Am Rev Respir Dis 1984; 130: 175-178.

19 Wilcox PG, Paré PD, Road JD, Fleetham JA. Respiratory muscle function during obstructive sleep apnoea. Am Rev Respir Dis 1990; 142: 533-539.

20 Kyroussis D, Polkey MI, Hamnegård CH, Mills GH, Green M, Moxham J. Respiratory muscle activity in patients with COPD walking to exhaustion with and without pressure support. Eur Respir J 2000; 15: 649-655.

21 Montserrat JM, Kosmas EN, Cosio MG, Kimoff RJ. Lack of evidence for diaphragmatic fatigue over the course of the night in obstructive sleep apnoea. Eur Respir J 1997; 10: 133-138.

22 Griggs GA, Findley LJ, Suratt PM, Esau SA, Wilhoit SC, Rochester DF. Prolonged relaxation rate of inspiratory muscles in patients with sleep apnea. Am Rev Respir Dis 1989; 140: 706-710.

23 McGuire M, MacDermott M, Bradford A. Effects of chronic intermittent asphyxia on rat diaphragm and limb muscle contractility. Chest 2003; 123: 875-881.

24 Cibella F, Cuttitta G, Romano S, Bellia V, Bonsignore G. Evaluation of diaphragmatic fatigue in obstructive sleep apnoeas during non-REM sleep. Thorax 1997; 52: 731-735.

25 El-Kabir DR, Polkey MI, Lyall RA, Williams AJ, Moxham J. The effect of treatment on diaphragm contractility in obstructive sleep apnoea syndrome. Respir Med 2003; 97: 1021-1026.

26 Bellemare F, Bigland-Ritchie B. Central components of diaphragmatic fatigue assessed by phrenic nerve stimulation. J Appl Physiol 1987; 62: 1307-1316.

27 Beck J, Sinderby C, Lindström L, Grassino A. Effects of lung volume on diaphragm EMG signal strength during voluntary contractions. J Appl Physiol 1998; 85: 1123-1134.

28 Sinderby C, Navalesi P, Beck J, et al. Neural control of mechanical ventilation in respiratory failure. Nat Med 1999; 5: 1433-1436.

29 Berry RB, McNellis MI, Kouchi K, Light RW. Upper airway anesthesia reduces phasic genioglossus activity during sleep apnea. Am J Respir Crit Care Med 1997; 156: 127-132.

30 Sleep-related breathing disorders in adults: recommendations for syndrome definition and measurement techniques in clinical research. The Report of an American Academy of Sleep Medicine Task Force. Sleep 1999; 22: 667-689.

31 Guilleminault C, Stoohs R, Clerk A, Cetel M, Maistros P. A cause of excessive daytime sleepiness. The upper airway resistance syndrome. Chest 1993; 104: 781-787.

32 Li KK, Kushida C, Powell NB, Riley RW, Guilleminault C. Obstructive sleep apnea syndrome: a comparison between Far-East Asian and white men. Laryngoscope 2000; 110: 1689-1693.

33 Argod J, Pépin JL, Lévy P. Differentiating obstructive and central sleep respiratory events through pulse transit time. Am J Respir Crit Care Med 1998; 158: 1778-1783.

34 Bradley TD, Logan AG, Kimoff RJ, et al. Continuous positive airway pressure for central sleep apnea and heart failure. N Engl J Med 2005; 353: 2025-2033. 